DOI: 10.12731/2658-4034-2020-5-35-56

УДК 378.4.147

\title{
ПРЕПОДАВАНИЕ ИНОСТРАННОГО ЯЗЫКА С ИСПОЛЬЗОВАНИЕМ LMS МООDLЕ В ВУЗЕ: ДИДАКТИЧЕСКИЕ ПОДХОДЫ К ОРГАНИЗАЦИИ ОБРАЗОВАТЕЛЬНОГО ПРОЦЕССА
}

\author{
Глотова А.В., Зубкова М.А.
}

В работе рассматриваются современные дидактические подходы к обучению иностранному языку на базе платформы Moоdle, обеспечивающие результативность иноязычного образования 8 условиях новых моделей и форм педагогического взаимодействия в системе высшей школь.

Целью исследования является анализ реализации и внедрения электронного учебного курса, созданного на базе LMS Moodle $u$ спроектированного на основе современных дидактических подходов к обучению иностранному языку в условиях электронной информационно-образовательной среды вуза, которые обеспечивают продуктивность иноязычного образования в контексте интегрирования новых моделей и форм педагогического взаимодействия.

Авторы анализируют дидактические подходы, применяемые при обучении иностранному языку с использованием LMS Moodle: личностно-ориентированньй, системно-деятельностный, фасилитативный, комплексный и средовой. Также представлены структура и содержание электронного учебного курса по дисииплине «Иностранный язык», разработанного в соответствии с исследуемыми дидактическими подходами на платформе Moоdle Севастопольского государственного университета.

В статье рассматриваются учебные действия студентов и формы педагогического взаимодействия, предусмотренные при проектировании содержания и выборе элементов построения 
курса. В работе использованы теоретические методы организации исследования: изучение и анализ источников научной, методической литературы, а также педагогического опыта, синтез и конкретизация понятий.

Результаты: в статье также представлен опьт разработки и внедрения электронного учебного курса «Английский язык» для студентов программы подготовки бакалавриата, который был создан преподавателями кафедры иностранных языков Института общественных наук и международных отношений Севастопольского государственного университета на базе LMS Moodle $в$ соответствии с рассматриваемьми подходами. Проанализировань особенности элементов электронного курса в рамках реализации обсуждаемьх подходов.

Область применения результатов: исследование представляет собой интерес для педагогических работников, интересующихся методическими вопросами проектирования и создания электронных учебных курсов по дисциплине «Иностранный язык» на базе LMS Moodle.

Ключевые слова: личностно-ориентированный подход; системно-деятельностный подход; фасилитативный подход; комплексный подход; средовой подход; иностранный язык; LMS Moоdle.

\section{FOREIGN LANGUAGE TEACHING VIA LMS MOODLE AT THE UNIVERSITY: DIDACTIC APPROACHES TO THE ORGANIZATION OF THE EDUCATIONAL PROCESS}

\section{Glotova A.V., Zubkova M.A.}

The paper analyzes modern pedagogical approaches to foreign language teaching via Moodle learning platform. The approaches studied ensure the effectiveness of foreign language education in the context of new models and forms of pedagogical interaction in the system of higher education.

The aim of the study is to examine the implementation and beta-testing of an eLearning course based on LMS Moodle. The course has been 
designed in compliance with modern didactic approaches to foreign language teaching in an online learning environment of the university. The approaches ensure the effectiveness of modern foreign language education in the context of new models and forms of pedagogical interaction.

The authors analyze the didactic approaches used in foreign language teaching via LMS Moodle: personality-oriented, system and activity-based, facilitative, integrated and environmental approaches. Also, the study focuses on the characteristics of the structure and content of the eLearning course for "Foreign Language" discipline, designed on the Moodle platform of Sevastopol State University incorporating the didactic approaches under review. The students learning activities and the forms of pedagogical interaction within the course structure are examined in the article.

The theoretical methods of research include conducting comprehensive analysis of scientific, methodological pedagogical literature sources as well as considering pedagogical experience, synthesis and concretization of the concepts.

Results: the article also presents the experience of the design and beta-testing of an eLearning course "English" for students of the Bachelor's degree program, which was created by the lecturers of Foreign Languages Department of the Institute of Social Sciences and International Relations of Sevastopol State University based on LMS Moodle according to the approaches considered. The characteristics of various course tools and elements reflecting the approaches are given in the paper.

Practical implications: the research is useful for educators interested in methodological issues of designing "Foreign language" eLearning courses based on LMS Moodle.

Keywords: personality-oriented approach; system and activity-based approach; facilitative approach; integrated approach; environmental approach; foreign language; LMS Moodle.

Важная роль в определении современной политики цифровой трансформации образовательного процесса в высшей школе Российской Федерации отводится подготовке будущих квалифицированных конкурентоспособных профессионалов, умеющих быстро и 
эффективно ориентироваться и взаимодействовать в условиях развивающейся цифровой среды. В связи с происходящими изменениями в становлении цифрового общества, а также необходимостью реализации положений утвержденной программы Правительства РФ «Цифровая экономика Российской Федерации» от 28 июля 2017 г., значительное внимание исследователей уделяется внедрению новых педагогических подходов, методов и технологий обучения, необходимых для проведения цифровой трансформации традиционной системы образования [6]. Среди актуальных проблем педагогических исследований стоит отметить следующие направления в контексте цифровизации системы высшей школы:

- вопросы, связанные с гуманизацией «цифрового образования» при активном интегрировании современных цифровых образовательных и информационно-коммуникативных технологий в учебный процесс вуза;

- формирование и развитие комплекса личных и профессиональных качеств выпускников в условиях цифровой трансформации традиционного образовательного процесса;

- пересмотр и уточнение содержания универсальных и профессиональных компетенций выпускников, а также разработка психолого-педагогических условий их формирования в высшем учебном заведении;

- анализ проведения и оценивание результатов этапов осуществления цифровизации вузов.

Актуальность нашего исследования определена необходимостью соблюдения педагогических подходов цифровой дидактики при проектировании и реализации электронного курса по иностранному языку для бакалавров в условиях электронной информационно-образовательной среды вуза. Данные подходы обеспечивают продуктивную иноязычную образовательную деятельность студентов как самостоятельно, так и совместно с преподавателем.

Содержание современного образования в высшей школе обуславливается совокупностью многих факторов. В педагогике используется базовое определение: «Содержание образования - педагогически 
адаптированная система научных знаний, связанных с ними практических умений и навыков, которыми необходимо овладеть» [5, c. 149]. Качество «цифрового образования» зависит не только от пересмотра содержания и обновления форматов учебного процесca, но и от комплекса целесообразно выбранных методов, подходов, принципов и форм педагогического взаимодействия. В. И. Блинов полагает, что «в цифровом образовательном процессе технологии и методы обучения приобретают свойство учебного содержания», что, в свою очередь, обеспечивает деятельность содержания образования [3, с. 28]. В современных условиях уровень и показатели качества образования являются важными характеристиками, определяющими конкурентоспособность как отдельно взятых учебных заведений, так и национальных систем образования в целом.

В настоящее время в университетах РФ образовательный процесс предусматривает новые модели дистанционного взаимодействия на базе систем управления обучением (англ. "Learning Management System” или LMS), например, Moodle (от англ. "Modular ObjectOriented Dynamic Learning Environment" - Модульная объектноориентированная динамическая обучающая среда). Московский государственный университет (МГУ), Национальный исследовательский ядерный университет «МИФИ» (НИЯУ МИФИ), Московский физико-технический институт (МФТИ), Севастопольский государственный университет (СевГУ), Филиал МГУ имени М. В. Ломоносова в г. Севастополе и другие вузы используют платформу Moodle для организации непрерывного образовательного процесса за счет интегрирования дистанционного или смешанного форматов обучения.

Широкий инструментарий ресурса Moodle используется для организации комплексного учебного процесса. Площадка Moodle также позиционируется как система дистанционного обучения (СДО) и является основой создания и разработки электронной-информационной образовательной среды учебных заведений. Считаем необходимым отметить, что важным преимуществом LMS Moodle c точки зрения Н.В. Худолей «является комплексность, состоящая в наличии множества разнообразных элементов и ресурсов, которые 
помогают преподавателю иностранного языка отобрать и систематизировать языковой и речевой материал с учетом его коммуникативной целесообразности и активной коммуникативности, подать его в интересной форме, а также обобщить материалы в единое целое» $[10$, с. 385$]$.

Преподавание иностранного языка имеет определенные специфические особенности, которые обуславливают выбор оптимальной образовательной платформы, соответствующей поставленным требованиям и ожидаемым результатам. Возможности системы Moodle позволяют организовать эффективный процесс изучения иностранного языка, проводимый в едином веб-пространстве за счет наличия инструментов, подходящих для создания интерактивного мультимедийного образовательного контента, управления учебной деятельностью студентов, обеспечения коммуникации и внедрения разнообразных форм педагогического взаимодействия [12].

Однако активное использование платформы Moodle и других элементов электронного обучения в преподавании иностранного языка выявило проблему недостаточного уровня методического обеспечения учебного процесса в обновленном формате и необходимость разработки системы продуктивных педагогических подходов, повышающих эффективность иноязычного образования.

Целью исследования является анализ реализации и внедрения электронного учебного курса на базе LMS Moodle, спроектированного на основе современных дидактических подходов к обучению иностранному языку в условиях электронной информационно-образовательной среды вуза, которые обеспечивают результативность современного иноязычного образования в условиях новых моделей и форм педагогического взаимодействия.

В рамках поставленной цели необходимо решить следующие задачи:

- проанализировать дидактические подходы, применяемые при обучении иностранному языку с использованием LMS Moodle;

- охарактеризовать структуру и содержание электронного учебного курса по дисциплине «Иностранный язык», разработан- 
ного в соответствии с рассматриваемыми дидактическими подходами на платформе Moodle Севастопольского государственного университета;

- рассмотреть учебные действия студентов и формы педагогического взаимодействия сторон образовательного процесса, предусмотренные при проектировании содержания и выборе элементов построения курса по иностранному языку на базе LMS Moodle.

В работе использованы теоретические методы проведения педагогических исследований: анализ научно-методической и психолого-педагогической литературы, синтез, дедукция и индукция, направленные на определение педагогических подходов, соответствующих требованиям современного языкового образования в контексте цифровой дидактики. В исследовании также описан опыт использования платформы Moodle для разработки авторского электронного учебного курса преподавателей кафедры иностранных языков Института общественных наук и международных отношений Севастопольского государственного университета (далее - ИОНМО СевГУ), предназначенного для обучения бакалавров иностранному языку в смешанном формате образовательного процесса в вузе.

Важным требованием «цифрового образования» является формирование гармоничной всесторонне развитой личности. Именно личность и деятельность человека определяют уровень развития общества или социума, внутри которого происходит дальнейшее взаимодействие всех его представителей в разных формах. Формирование личности студента с учетом индивидуальных особенностей, а также развитие личностных и профессиональных качеств выпускников вуза представляет собой комплексный процесс, охватывающий не только непосредственное приобретение теоретических знаний, овладение профессиональными навыками и умениями, но и приобщение к основам современной мировой культуры и становления цифрового общества. Соответственно, основным направлением высшего образования является развитие внутреннего потенциала каждого студента. 
Дисциплина «Иностранный язык» является неотъемлемой частью образовательного процесса студентов в вузах Российской Федерации согласно Федеральному государственному образовательному стандарту высшего образования нового поколения, поскольку комплексно связана с формированием ряда приоритетных универсальных, общепрофессиональных и профессиональных компетенций (например, «Коммуникация», «Межкультурное взаимодействие», «Командная работа и лидерство», «Самоорганизация и саморазвитие», «Разработка и реализация проектов» и так далее) [8].

Формирование обозначенных компетенций является основой для осуществления взаимодействия в цифровом обществе и требует обоснованного выбора педагогических подходов и приемов. Проблема развития навыков 21 века посредством использования цифровых образовательных технологий на занятиях по иностранному языку детально рассматривается в публикациях Н. Б. Самойленко, Н. Ю Фоминых [7; 9]. Среди современных подходов, применяемых при обучении иностранному языку в условиях цифровой трансформации вузов следует выделить личностно-ориентированный, системно-деятельностный, фасилитативный, комплексный и средовой.

В настоящее время в преподавании иностранного языка в системе высшей школы произошел явный переход от учебно-дисциплинарной модели взаимодействия педагога и учащихся к личностно-ориентированному обучению, в центре которого основную ценность имеет непосредственно «личность обучаемого», его образовательные потребности и интересы. Личностно-ориентированный подход учитывает, в первую очередь, индивидуальные предпочтения и способности студентов. Содержание данного подхода предполагает, что организация учебного процесса, выбор методических приемов и педагогических стратегий преподавателя, способ подачи учебного материала и структура заданий должны преломляться через призму личности обучаемого, его потребностей, мотивов, уровня активности и других индивидуальных и психологических особенностей. LMS Moodle обеспечивает решение проблемы построения индивидуальной образовательной траектории, поскольку препо- 
даватель имеет возможность создавать электронные курсы с учетом уровня владения иностранным языком обучающихся, а также варьировать содержание учебных модулей, создавать динамичный мультимедийный контент и планировать интерактивные формы работы, что способствует самостоятельной учебной и познавательной деятельности студентов [14].

Также при обучении иностранному языку активно внедряются педагогические инновации, которые ориентированы на практико-ориентированную деятельность студентов в условиях межличностного взаимодействия в цифровой образовательной среде. Стоит отметить, что современные студенты, являясь представителями «цифрового поколения», позитивно относятся к организации образовательного процесса с применением дистанционных технологий. Таким образом, следующий важный подход к языковому образованию на базе системы обучения Moodle в высшей школе - это системно-деятельностный, направленный на развитие учебной автономии студента и развитие критического мышления. Сегодня обучающиеся должны быть способны самостоятельно получать знания, анализировать их содержание и принимать решения на основе проведенного анализа поступающей информации. Используя данный подход, необходимо соблюдать принцип единства теории, эксперимента и практики. Оба рассматриваемых выше подхода нацелены на вовлечение студентов в обучение и развитие их творческого потенциала, поскольку учащиеся являются активными участниками познавательной и учебно-исследовательской деятельности при организации образовательного процесса на платформе Moodle. Более того, при системно-деятельностном подходе приобретенные новые знания должны преобразовываться в необходимые профессиональные компетенции.

Инструменты платформы Moodle позволяют преподавателю иностранного языка применять технологию разноуровнего обучения, организовывать коллективное взаимообучение, разрабатывать задания для взаимопроверки, проектировать модульное обучение. В рамках дисциплины «Иностранный язык» LMS Moodle расширяет возможности применения активных методов обучения. 
Стоит отметить, что новый формат преподавания иностранного языка с использованием системы управления обучением существенно изменяется роль педагога. Современный преподаватель высшей школы рассматривается как собеседник, наставник, исследователь, фасилитатор, тьютор, модератор, супервизор, эксперт, курирующий работу студента в новой образовательной среде. На сегодняшний день задача педагога - развивать критическое и системное мышление студентов, учить работать с огромным потоком поступающей информации в процессе изучения иностранного языка за пределами аудитории. Следовательно, необходимо определить педагогические условия, которые будут мотивировать студента к самообразованию в новой среде, на что ориентировано применение фасилитативного подхода.

В условиях обучения на базе LMS Moodle преподаватель-фасилитатор организует и курирует процесс группового взаимодействия и коммуникации, координирует работу группы, распределяет роли в командах учащихся для создания площадки обсуждения различных актуальных вопросов и эффективного решения поставленных задач [1]. Фасилитативный подход позволяет активизировать студентов, пробуждая интерес к познавательной деятельности, участию в дискуссиях. По мере коллективного обсуждения проблемных вопросов выявляются различные противоположные точки зрения, предлагаются и аргументируются новые идеи, происходит естественный процесс познания. Опции системы Moodle «Семинар», «Форум», «Вики» позволяют планировать формы работы, построенные на элементах дискуссии и совместной работы студентов.

Преподаватель-фасилитатор устанавливает партнерские отношения в условиях равноправного сотрудничества, совместно со студентами планирует учебный процесс и выбирает наиболее приемлемые методы обучения в гибкой цифровой среде. Таким образом, преподаватель использует механизм фасилитирующего воздействия в ходе диалогического общения, способствуя решению коммуникативных задач [11].

Преподавание иностранного языка с использованием системы управления обучением Moodle должно строиться также с учётом комплексного подхода. Суть комплексного подхода заключается в 
единстве обучения, воспитания и развития. По мнению К.И. Бузарова, комплексный подход - это «способ интеграции всей совокупности условий и факторов, имеющих прямое или косвенное отношение к формированию личности», а также «методологический и организационный, управленческий принцип, метод мышления, познания и решения воспитательных и иных задач» [2, с. 34]. Данный подход позволяет организовать совместную творческую образовательную деятельность на базе платформы Moodle, поскольку педагог может задействовать широкий спектр опций ресурса.

LMS Moodle является также частью электронной информационно-образовательной среды вуза, что обуславливает необходимость анализа использования средового подхода в цифровой дидактике. Основной целью реализации средового подхода является обеспечение всесторонней социализации и эффективной адаптации студентов к обучению в условиях технологически обновленной образовательной среды вуза. Средовой подход подразумевает, что учебно-воспитательный процесс может быть организован с учетом выбора учащимися места, времени, программ, форм и методов обучения. Данный подход позволяет управлять образовательным процессом, нацеленным на самообучение, самовоспитание и саморазвитие в гибкой образовательной среде университета.

Реализация средового подхода учитывает следующие факторы: интенсивное развитие средств коммуникации, факт размытия социально-экономических границ взаимодействия, необходимость распределения аудиторной и внеаудиторной нагрузки, изменения условий труда, характера, принципов и форм организации образовательного процесса, принципы реализации средового подхода (опосредованности, технологичности, вариативности), особенности проектирования инновационной образовательной среды вуза.

Далее рассмотрим пример организации процесса преподавания иностранного языка с использованием LMS Moodle в системе высшей школы. СевГУ активно внедряет в учебно-воспитательный процесс передовые цифровые образовательные технологии. В университете используется система дистанционного обучения eLearning на базе 
виртуальной обучающей среды Moodle. В ИОНМО СевГУ преподаватели кафедры иностранных языков разработали и внедрили онлайн курсы для студентов бакалавриата различных направлений подготовки (https://testmoodle.sevsu.ru/course/index.php?categoryid=55). Курсы предназначены для обучения иностранному языку в смешанном формате (комбинирование традиционных практических занятий в аудитории с применением элементов электронных учебных курсов для организации самостоятельной работы студентов) [4].

Авторский электронный учебный курс «Английский язык» (Уровень 4_INTERMEDIATE_B1+, Part 1, Part 2) ориентирован на индивидуальное освоение материала и организацию самостоятельной работы студентов очной и заочной форм обучения всех направлений подготовки в СевГУ. Цель курса - формирование языковых компетенций и развитие иноязычных коммуникативных навыков на уровне Intermediate (пороговый уровень). Общая трудоемкость составляет 108 академических часов, включая 36 академических часов, предусмотренных на добавление и пересмотр преподавателем учебного материала в соответствии с потребностями определенной группы.

Созданный курс используется в качестве дополнительного материала к учебнику Cambridge English Empower (уровень Intermediate B1+) и состоит из двух частей, каждая из которых рассчитана на один семестр (https://testmoodle.sevsu.ru/course/view.php?id=304, https://testmoodle.sevsu.ru/course/view.php?id=306).

Рассматриваемый электронный учебный курс имеет четкую структуру. Во введении представлены краткое описание и общие сведения касательно планируемой учебной деятельности студентов, обозначены цели, задачи и тематические разделы. Для повышения мотивации обучающихся в начале курса размещена видео-презентация, содержащая основные требования к освоению материала и организации работы.

Каждый раздел курса состоит из четырех частей с последующим тестированием для проведения контроля и фиксации академических успехов студентов по мере освоения материала. Часть А и часть В ориентированы на изучение и отработку лексических и граммати- 
ческих аспектов, часть С направлена на развитие коммуникативных навыков (монологической и диалогической речи студентов), часть D предназначена для формирования навыков письма. Особое внимание уделяется качеству оценивания [15], журнал оценок курса настроен по средневзвешенному баллу, задания настроены с разными уровнями приоритетности.

Рассмотрим инструменты платформы Moodle с целью определения их значимости и продуктивности при организации аудиторной или самостоятельной работы студентов в рамках электронного учебного курса по иностранному языку. Каждый урок состоит из 20 заданий и включает видео-презентацию, интерактивный тематический план и краткое описание урока. Видеоконтент позволяет повысить вовлеченность студентов в учебный процесс [13]. Аудио- и видеоподкасты создаются как преподавателями, так и студентами. Подкаст - это аудио- или видеофайл, записанный одним или несколькими людьми с последующим размещением в сети Интернет. Данный файл доступен для просмотра, воспроизведения и скачивания. Например, преподаватели используют подкасты для закрепления грамматического материала, записывая теоретический материал, а также презентации PowerPoint, создаваемые по типу слайд-шоу с комментариями преподавателя и примерами практического применения изученного материала. В рамках курса студентам предлагается самостоятельно создать аудио- или видеоподкаст на заданную тему. Данный вид работы может быть выполнен индивидуально или в группе и позволяет создать наглядные языковые ситуации для учебных целей на иностранном языке. Содержание аудио- и видеоподкастов определяется в соответствии с требованиями учебной программы. Цель записи - развитие всех видов речевой деятельности. Стоит отметить, что ежегодно в СевГУ проводится конкурс видеоподкастов на иностранном языке среди студентов первого года обучения.

В разработанном электронном учебном курсе используются следующие структурные элементы:

- «Извещение» (раздел предназначен для публикации объявлений, новостей, анонсов и уведомлений от преподавателя); 
- введение в онлайн-курс Intermediate B1+ (обзор структуры курса);

- содержание онлайн-курса (раздел, разработанный с использованием интерактивных элементов и инфографики для наглядного представления тематического наполнения и содержания курса);

- журнал посещаемости (управление учебной деятельностью студентов, фиксация посещаемости и успеваемости студентов);

- «Глоссарий» (список основных терминов для изучения в рамках курса);

- интерактивный элемент Н5Р (задания, нацеленные на закрепление пройденного материала);

- «Лекция» (последовательное изучение материала с проверочным тестом, содержащим вопросы по теме урока для проведения самоконтроля);

- «Тест» (проведение контрольных мероприятий с использованием одной или нескольких попыток, а также с возможностью ограничения времени на выполнение задания);

- «Задание» (упражнения, направленные на развитие коммуникативных навыков и умений с возможностью представить развернутые ответы на вопросы в письменной форме, в виде презентации или подготовленного аудио/видеоматериала);

- «Семинар» (нацелен на актуализацию знаний учащихся, развитие критического мышления, а также их активное вовлечение в учебный процесс, позволяя стимулировать, учебно-познавательную и творческую деятельность студентов);

- пакет SCORM (набор файлов, упакованных в соответствии с согласованным стандартом для учебных объектов);

- «Форум» (возможность коммуникации и проведения консультации с преподавателем);

- «Анкета» (получение быстрой обратной связи и рефлексии);

- опросный лист (позволяет получить обратную связь);

- форум «Вопрос/Ответ» (площадка для обсуждения возникших вопросов и организации совместных дискуссий);

- библиография (список полезных и дополнительных информационных ресурсов). 
Обеспечение коммуникации является основополагающим условием при изучении иностранного языка. Платформа Moodle предусматривает использование встроенных инструментов коммуникации и форм синхронного и асинхронного педагогического взаимодействия, например, видеоконференция, чат, форум и другие.

При разработке содержания и структуры электронного учебного курса на базе LMS Moodle преподаватели кафедры иностранных языков ИОНМО СевГУ учитывали необходимость соблюдения основных рассматриваемых в нашем исследовании педагогических подходов, представленных в таблице 1.

Таблицуа 1.

Соответствие содержания и элементов курса реализации педагогических подходов в условиях цифровой дидактики

\begin{tabular}{|c|c|c|c|}
\hline Подход & $\begin{array}{c}\text { Элемент } \\
\text { курса на } \\
\text { базе LMS } \\
\text { Moodle } \\
\end{array}$ & $\begin{array}{c}\text { Реализация } \\
\text { подхода }\end{array}$ & $\begin{array}{c}\text { Особенности } \\
\text { применения элементов } \\
\text { электронного курса }\end{array}$ \\
\hline $\begin{array}{l}\text { Личност- } \\
\text { но-ориен- } \\
\text { тирован- } \\
\text { ный }\end{array}$ & $\begin{array}{l}\text { «Форум», } \\
\text { «Опрос», } \\
\text { «Семинар», } \\
\text { «Анкета», } \\
\text { «Тест», } \\
\text { «Лекция» }\end{array}$ & $\begin{array}{l}\text { Организация учебно- } \\
\text { го процесса с учетом } \\
\text { индивидуальных по- } \\
\text { требностей личности } \\
\text { обучаемого; распре- } \\
\text { деление учащихся } \\
\text { по уровням владе- } \\
\text { ния иностранным } \\
\text { языком; разработка } \\
\text { индивидуальных } \\
\text { тренировочных и те- } \\
\text { стовых заданий. } \\
\end{array}$ & $\begin{array}{l}\text { Элементы «Анкета», «Фо- } \\
\text { рум», «Опрос» и «Тест» } \\
\text { позволяют обозначить инди- } \\
\text { видуальные потребности у } \\
\text { учащихся и разработать за- } \\
\text { дания с их учетом. Студенты } \\
\text { отвечают на вопросы, позво- } \\
\text { ляющие определить уровень } \\
\text { владения языком, выявить } \\
\text { сферу профессиональных } \\
\text { интересов, а также отследить } \\
\text { динамику. }\end{array}$ \\
\hline $\begin{array}{l}\text { Систем- } \\
\text { но-дея- } \\
\text { тельност- } \\
\text { ный }\end{array}$ & $\begin{array}{l}\text { «Глоссарий», } \\
\text { «Вики», } \\
\text { «Лекция», } \\
\text { «Тест», «За- } \\
\text { дание», } \\
\text { «Семинар», } \\
\text { «Видеокон- } \\
\text { ференция» }\end{array}$ & $\begin{array}{l}\text { Процесс обучения } \\
\text { представляет со- } \\
\text { бой различные виды } \\
\text { целенаправленной } \\
\text { продуктивной иноя- } \\
\text { зычной образователь- } \\
\text { ной деятельности } \\
\text { и предусматривает } \\
\text { активное вовлечение } \\
\text { студентов в учебно- } \\
\text { познавательную и } \\
\text { поисковую деятель- } \\
\text { ность. } \\
\end{array}$ & $\begin{array}{l}\text { Блоки «Глоссарий» и «Вики» } \\
\text { нацелены на реализацию тех- } \\
\text { нологий «коллективного» и } \\
\text { «включенного» обучения. } \\
\text { Элемент «Видеоконференция» } \\
\text { позволяет продемонстрировать } \\
\text { студенту умение применять } \\
\text { изученный материал в кон- } \\
\text { кретных учебных условиях в } \\
\text { режиме реального времени, а } \\
\text { также способствует мотивации } \\
\text { обучающихся к принятию ак- } \\
\text { тивного участия в дискуссии. }\end{array}$ \\
\hline
\end{tabular}




\begin{tabular}{|c|c|c|c|}
\hline $\begin{array}{l}\text { Фасили- } \\
\text { тативный }\end{array}$ & $\begin{array}{l}\text { «Семинар», } \\
\text { «Чат», } \\
\text { «Форум», } \\
\text { «Анкета», } \\
\text { «Видеокон- } \\
\text { ференция», } \\
\text { «Опрос» }\end{array}$ & $\begin{array}{l}\text { Обучение на основе } \\
\text { многостороннего } \\
\text { сотрудничества и } \\
\text { партнерского вза- } \\
\text { имодействия. Вне- } \\
\text { дрение технологии } \\
\text { взаимообучения и } \\
\text { элементов взаимоо- } \\
\text { ценивания. }\end{array}$ & $\begin{array}{l}\text { Элемент «Семинар» } \\
\text { позволяет студенту } \\
\text { выбрать направление для } \\
\text { исследования в рамках } \\
\text { предложенной тематики, } \\
\text { представить свой вариант } \\
\text { решения проблемы, а } \\
\text { также дать развернутые } \\
\text { аргументированные ответы } \\
\text { на вопросы в письменной } \\
\text { форме. } \\
\text { Преподаватель использует } \\
\text { технологию взаимообучения, } \\
\text { руководствуясь принципом } \\
\text { индивидуализации } \\
\text { образовательного процесса. } \\
\text { Материалы семинара } \\
\text { оцениваются совместно } \\
\text { учащимися с использованием } \\
\text { заранее установленных } \\
\text { критериев. Студенты } \\
\text { могут получить оценки за } \\
\text { предоставленную работу, } \\
\text { а также за проведение } \\
\text { оценивания материалов } \\
\text { сокурсников в соответствии с } \\
\text { заданными критериями. } \\
\text { Данный элемент позволяет } \\
\text { стимулировать, учебно- } \\
\text { познавательную, творческую } \\
\text { и аналитическую } \\
\text { деятельность студентов; } \\
\text { развивать критическое } \\
\text { мышление. }\end{array}$ \\
\hline $\begin{array}{l}\text { Ком- } \\
\text { плексный }\end{array}$ & $\begin{array}{l}\text { «Видеокон- } \\
\text { ференция», } \\
\text { «Глоссарий», } \\
\text { «Лекция», } \\
\text { «Задание», } \\
\text { «Тест», «Фо- } \\
\text { рум», «Анке- } \\
\text { та», «Пакет } \\
\text { SCORМ», } \\
\text { «Опрос», } \\
\text { «Семинар», } \\
\text { «Чат» }\end{array}$ & $\begin{array}{l}\text { Многообразие } \\
\text { видов и форм пе- } \\
\text { дагогического } \\
\text { взаимодействия. } \\
\text { Проектирование } \\
\text { содержания и инте- } \\
\text { рактивного мульти- } \\
\text { медийного учебного } \\
\text { контента в соответ- } \\
\text { ствии с целями, } \\
\text { задачами и требо- } \\
\text { ваниями дисципли- } \\
\text { ны «Иностранный } \\
\text { язык». }\end{array}$ & $\begin{array}{l}\text { Элемент «Задание» дает воз- } \\
\text { можность преподавателю } \\
\text { варьировать содержание } \\
\text { учебного контента, разноо- } \\
\text { бразить формы представле- } \\
\text { ния материала студентов, а } \\
\text { также оставлять отзывы в } \\
\text { виде комментариев в процес- } \\
\text { се оценивания. }\end{array}$ \\
\hline
\end{tabular}


Окончание табл. 1.

\begin{tabular}{|c|c|c|c|}
\hline Средовой & $\begin{array}{l}\text { «Пакет } \\
\text { SCORM», } \\
\text { «Задание», } \\
\text { «Семинар», } \\
\text { «Лекция», } \\
\text { «Видеокон- } \\
\text { ференция», } \\
\text { «Чат», «Фо- } \\
\text { рум» }\end{array}$ & $\begin{array}{l}\text { Всесторонняя со- } \\
\text { циализация и эффек- } \\
\text { тивная адаптация } \\
\text { студентов в измен- } \\
\text { чивых социаль- } \\
\text { но-экономических } \\
\text { условиях и переходе } \\
\text { в технологически } \\
\text { обновленную обра- } \\
\text { зовательную среду } \\
\text { вуза. Обеспечение } \\
\text { стабильной ком- } \\
\text { муникации между } \\
\text { преподавателем и } \\
\text { студентами. }\end{array}$ & $\begin{array}{l}\text { Элемент «Чат» способству- } \\
\text { ет развитию иноязычных } \\
\text { коммуникативных навыков } \\
\text { студентов, а именно раз- } \\
\text { витию письменной речи на } \\
\text { иностранном языке. Данный } \\
\text { элемент позволяет поддер- } \\
\text { живать постоянную комму- } \\
\text { никацию участников курса, } \\
\text { а также обмениваться со- } \\
\text { общениями лично с препо- } \\
\text { давателем или отдельными } \\
\text { пользователями. } \\
\text { Пакет SCORM (набор фай- } \\
\text { лов, упакованных в соот- } \\
\text { ветствии с согласованным } \\
\text { стандартом для учебных объ- } \\
\text { ектов) позволяет работать } \\
\text { студентам с учебным матери- } \\
\text { алом в виде интерактивного } \\
\text { мультимедийного контента на } \\
\text { базе LMS Мооdlе. }\end{array}$ \\
\hline
\end{tabular}

В рамках исследования был проведен опрос студентов для выявления их мнения об организации образовательного процесса на базе LMS Moodle. Следует отметить, что значительная часть опрошенных бакалавров 1 и 2 курсов (61,9 \%) полагают, что новая форма организации учебного процесса при изучении иностранного языка с использованием электронных курсов на базе LMS Moodle положительно влияет на эффективность обучения. Также большинство студентов отметили интенсификацию языковой подготовки, использование продуктивных педагогических подходов и методов обучения иностранному языку.

Следует отметить, что представленный электронный курс прошел внутреннюю экспертизу в СевГУ, а также был удостоен III призового места в конкурсе на лучший онлайн-курс для студентов вузов («Лучший онлайн-курс Юга России», г. Ростов-на-Дону, 2020 г.). Организаторами конкурса выступили банк «Центр-Инвест» и Министерство информационных технологий и связи Ростовской области. Конкурс проходил в несколько этапов: предварительный отбор, электронное онлайн-голосование и экспертная оценка курса, общее 
число участников. Победителей определяло жюри в рамках экспертной оценки курсов и зрительское голосование, которое проходило на сайте проекта лучшийонлайнкурс.pф. (https:/online.don2050.ru/).

\section{Вывод}

В работе рассмотрены основные педагогические проблемы иноязычного образования в условиях цифровизации системы высшей школы: необходимость обеспечения непрерывности образовательного процесса, специфика выбора оптимальной образовательной платформы, организация коммуникации и соблюдение интерактивности обучения, интегрирование разнообразных форм педагогического взаимодействия, ориентированных на активное вовлечение студентов в учебно-познавательную деятельность, формирование навыков совместного обучения и самостоятельной работы с использованием LMS Moodle. В ходе исследования были проанализированы сущность и содержание педагогических подходов, используемых в преподавании иностранного языка на базе платформы Moodle: личностно-ориентированный, системно-деятельностный, фасилитативный, комплексный и средовой, обуславливающие результативность образовательного процесса в обновленной среде вуза. Рассмотрены функциональные возможности системы Moodle для решения широкого спектра педагогических задач при изучении иностранного языка в условиях электронного обучения.

Представлен обзор структуры и особенности использования элементов электронного учебного курса по иностранному языку на базе LMS Moodle СевГУ. Специфика данного курса позволяет координировать учебные действия студентов и проектировать формы педагогического взаимодействия сторон образовательного процесса на основе педагогических подходов цифровой дидактики. Приобретенный опыт и результаты опроса студентов позволили обозначить перспективные направления для дальнейших исследований.

\section{Список литературы}

1. Адонина Л. В., Вишнякова А.В., Кузёма Т.Б. Pedagogical facilitation basics in the modern educational process // Информационная Мор- 
довия. E-SCIO: электронный журнал, 2020. № 5 (44). С. 605-611. URL: https://www.elibrary.ru/item.asp?id=42988979 (дата обращения: 25.11.2020).

2. Бузаров К.И. Комплексный подход как методологический принцип построения воспитательной системы школы (теоретический аспект) // Вестник Адыгейского государственного университета. Педагогика и психология. Майкоп. 2012. № 3. C. 32-36. URL: https://www. elibrary.ru/item.asp?id=17966225 (дата обращения: 25.11.2020).

3. Дидактическая концепция цифрового профессионального образования и обучения / П.Н. Биленко, В.И. Блинов, М.В. Дулинов, Е.Ю. Есенина, А.М. Кондаков, И.С. Сергеев; под науч. ред. В.И. Блинова, $2020.98 \mathrm{c}$.

4. Игнатенко И.И. Технология смешанного обучения системы MOODLE // Современное языковое образование: инновации, проблемы, решения: сб. науч. трудов. М., 2016. С. 15-18.

5. Педагогика: учебник для бакалавров / Л.П. Крившенко [и др.]; под ред. Л.П. Крившенко. 2-е изд., перераб. и доп. М.: Проспект, 2015. $488 \mathrm{c}$.

6. Программа «Цифровая экономика Российской Федерации» // Правительство Российской Федерации, 2017. URL: http://static.government. ru/media/files/9gFM4FHj4PsB79I5v7yLVuPgu4bvR7M0.pdf (дата обращения: 25.11.2020).

7. Самойленко Н.Б. Foreign language educational platforms for undergraduate students' language professional communication training // Материалы $\mathrm{V}$ научного конгресса / под. ред. Е.В. Полховская. Симферополь, 2020. C. 52-56.

8. Федеральный государственный образовательный стандарт высшего образования ГОС ВО (3++). URL: http://fgosvo.ru/fgosvo/151/150/24 (дата обращения: 25.11.2020).

9. Фоминых Н.Ю., Афанасьев М.А. Электронное обучение как новая форма учебно-воспитательного процесса // Ученые записки Ульяновского государственного университета. «Актуальные проблемы теории языка и лингводидактики». Сер.: Лингвистика. Вып. 1(22) / под ред. Фефилова А.И. Ульяновск, 2018. С. 23-27. 
URL: https://www.elibrary.ru/item.asp?id=36547601 (дата обращения: 25.11.2020).

10. Худолей Н.В. Использование LMS Moodle при обучении иностранному языку в вузе (опыт ФГБОУ «Красноярский ГАУ») // Вестник РУДН. Сер.: Информатизация образования. 2018. Т. 15. № 4. С. 410 423. doi:10.22363/2312-8631-2018-15-4-410-423.

11. Díaz Redondo, R.P., Caeiro Rodríguez, M., López Escobar, J. et al. Integrating micro-learning content in traditional e-learning platforms. Multimed Tools Appl 80, 2020. pp. 3121-3151. https://doi. org/10.1007/s11042-020-09523-Z.

12. Farias, Fabrícia \& Sales, Gilvandenys \& Gonçalves, Alexandra \& Machado, Adriano \& Leite, Eliana. Analyses of the Flipped Classroom Application in Discussion Forum on LMS Moodle. 2017. pp. 690-700. doi:10.1007/978-3-319-56538-5_70.

13. Gamage, S.H.P.W., Ayres, J.R., Behrend, M.B. et al. Optimising Moodle quizzes for online assessments. IJ STEM 2019. Ed. 6, 27. doi:10.1186/ s40594-019-0181-4.

14. Lapteva I.V. et al. Strategies of continuous foreign language training at higher school in professional interaction of non-linguistic specialists. Humanities \& Social Sciences Reviews. 2019. Vol. 7. No. 4. P. 103-110. URL: https://giapjournals.com/index.php/hssr/article/view/hssr.2019.7415 (дата обращения: 25.11.2020).

15. Santoso, Yulianto \& Hadiyanto, Hadiyanto. The Ability of Lecturers to Use Online Learning Approach Based on LMS Moodle. 2019. doi:10.2991/ picema-18.2019.54

\section{References}

1. Adonina L.V., Vishnyakova A.V., Kuzema T.B. Informatsionnaya Mordoviya [E-SCIO]. Saransk, 2020, no. 5 (44), pp. 605-611. https://www. elibrary.ru/item.asp?id=42988979 (accessed November 25, 2020).

2. Buzarov K.I. Vestnik Adygeyskogo gosudarstvennogo universiteta. Pedagogika i psikhologiya. [Bulletin of the Adyghe State University, Pedagogy and Psychology], Maykop, 2012, no 3, pp. 32-36. https://www. elibrary.ru/item.asp?id=17966225 (accessed November 25, 2020). 
3. Bilenko P.N., Blinov V.I., Dulinov M.V., Esenina E.Yu., Kondakov A.M., Sergeev I.S.; under scientific editorship V.I. Blinov Didakticheskaya kontseptsiya tsifrovogo professional'nogo obrazovaniya $i$ obucheniya [Didactic concept of digital vocational education and training]. 2020, $98 \mathrm{p}$.

4. Ignatenko I.I. Sovremennoe yazykovoe obrazovanie: innovatsii, problemy, resheniya: sb. nauch. trudov. [Modern language education: innovations, problems, solutions: collection of scientific papers.]. M., 2016. pp. $15-18$.

5. Krivshenko L.P. et al. Pedagogika: uchebnik dlya bakalavrov [Pedagogics: textbook for bachelors] under scientific editorship Krivshenko L.P. $2^{\text {nd }}$ ed., rev. and add. M.: Prospekt, 2015. 488 p.

6. Programma "Tsifrovaya ekonomika Rossiyskoy Federatsii" [Government of the Russian Federation], 2017. http://static.government.ru/media/ files/9gFM4FHj4PsB79I5v7yLVuPgu4bvR7M0.pdf (accessed November 25, 2020).

7. Samoylenko N.B. Materialy V nauchnogo kongressa. [Materials of the 5th scientific congress; under scientific editorship E.V. Polkhovskaya.]. Simferopol, 2020. pp. 52-56.

8. Federal'nyy gosudarstvennyy obrazovatel'nyy standart vysshego obrazovaniya GOS VO (3++). [Federal state educational standard of higher education GOS VO $(3++)]$. URL: http://fgosvo.ru/fgosvo/151/150/24 (accessed November 25, 2020).

9. Fominykh N.Yu., Afanas'ev M.A. Uchenye zapiski Ul'yanovskogo gosudarstvennogo universiteta. "Aktual'nye problemy teorii yazyka i lingvodidaktiki”. [Scientific notes of the Ulyanovsk State University. "Actual problems of the theory of language and linguodidactics"] Linguistics series. Issue 1 (22) under scientific editorship Fefilov A.I. Ulianovsk. 2018. pp. 23-27. URL: https://www.elibrary.ru/item.asp?id=36547601 (accessed November 25, 2020).

10.Khudoley N.V. Vestnik RUDN. Seriya: Informatizatsiya obrazovaniya. [RUDN Journal. Series: Informatization in Education] 2018. vol. 15. no. 4. pp. 410-423. doi:10.22363/2312-8631-2018-15-4410-423. 


\section{ДАННЫЕ ОБ АВТОРАХ}

Глотова Александра Валерьевна, старший преподаватель кафедры «Иностранные языки»

Филиал Московского государственного университета имени М.В. Ломоносова в г. Севастополе

ул. Ленинские горы, д. 1, г. Москва, 119991, Россия

glotova@glotova.com

Зубкова Мария Александровна, старший преподаватель кафедры «Иностранные языки»

Институт общественных наук и международных отношений Севастопольского государственного университета ул. Университетская, 33, г. Севастополь, 299053, Россия m.a.zubkova@gmail.com

\section{DATA ABOUT THE AUTHORS}

Glotova Aleksandra Valerevna, Senior lecturer, Foreign Languages Department

Lomonosov Moscow State University Branch in Sevastopol

1, Leninskie gory St., Moscow, 119991, Russian Federation glotova@glotova.com

SPIN-code: 9285-2528

ORCID: 0000-0002-0175-001X

Zubkova Mariya Aleksandrovna, Senior Lecturer, Foreign Languages Department Institute of Social Sciences and International Relations of Sevastopol State University

33, Universitetskaya St., Sevastopol, 299053, Russian Federation m.a.zubkova@gmail.com

SPIN-code: 2381-6388

ORCID: 0000-0001-8330-4330 